\title{
Features of Use of Rapid Prototyping Technology in the Manufacture of Wax Models of GTE Turbine Blades
}

\author{
R.A. Vdovin ${ }^{1, *}$ \\ ${ }^{1}$ Samara University, 34 Moskovskoe sh., Samara, Russia, 443086
}

\begin{abstract}
The paper presents the main results related to the peculiarities of using 3D printing technology and methods of rapid prototyping in the manufacture of wax models of blades of a GTE turbine. The main design solutions that must be used in the design of a blade blank are presented in detail: the total shrinkage coefficient, equidistant rolling of the airfoil profile, allowance along tract surfaces, radial fillets, and a number of others. The results of control of geometric dimensions of the turbine blade blanks at the corresponding stages of the technological process showed deviations from the nominal value within the tolerance range for the executable dimensions, and the statistical information from the measurement of an experimental batch of wax models of blade blanks showed stability of the silicone tooling and ability to manufacture a series of wax models of the blades in the amount of 100 pieces when using one mold.
\end{abstract}

\section{Introduction}

Modern promising engine building is aimed at obtaining complex-profile parts with a developed spatial geometry with a lower cost price and improved quality characteristics. Turbine blade castings, which belong to this class of parts, are manufactured using investment casting technologies. It is advisable to obtain this technology in the manufacture of thin-walled high-precision castings from refractory materials that are difficult to machine [1].

Obtaining complex-profile castings of GTE blades with dimensional and precision parameters specified in the design documentation is one of the main tasks of the foundry. Investment casting technology is called precision casting, which enables production of complex shaped castings with minimal machining allowances, therefore, this method can significantly reduce material costs. However, this method is not devoid of disadvantages, the main of which are: high cost of castings, high percentage of defective products, outdated methods of control and production. In connection with these shortcomings, it is advisable to consider an improved process for manufacturing turbine blade castings using $3 \mathrm{D}$ printing technology and rapid prototyping methods [2].

\footnotetext{
${ }^{*}$ Corresponding author: vdovin.ssau@gmail.com
} 


\section{Experimental}

The stage of preparation and pilot testing of the technology for manufacturing turbine blades by rapid prototyping should begin with the design of a 3D model of the blade casting (Figure 1), taking into account shrinkage of the material at each operation of the technological process $[3,4]$.
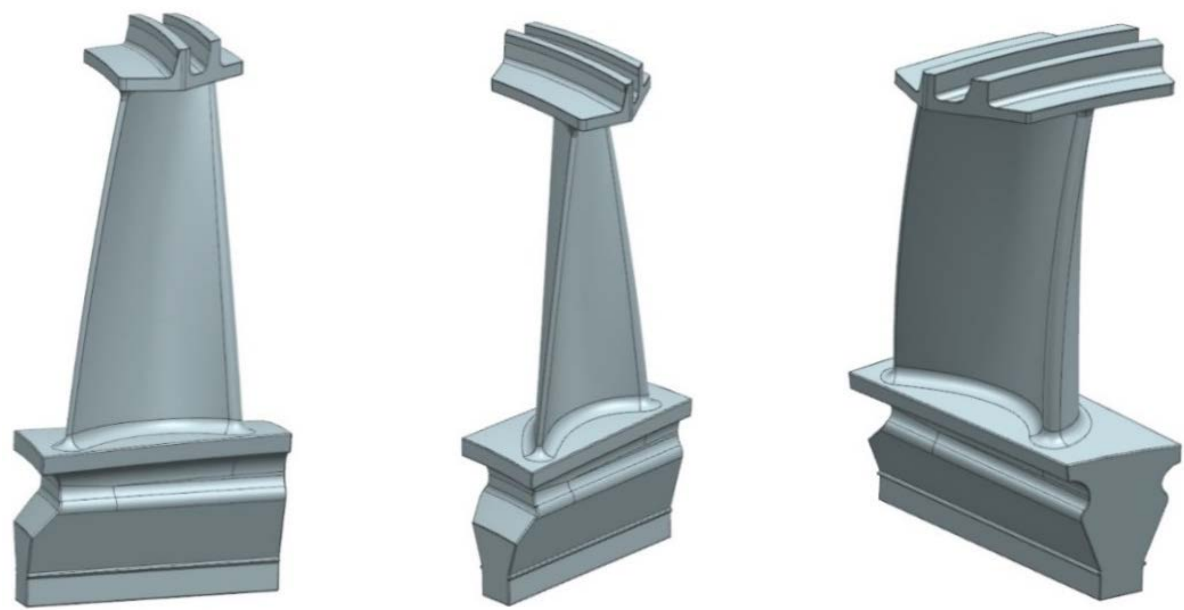

Fig. 1. 3D model of a GTE turbine blade's blank.

The volumetric shrinkage value was determined according to the methodology for the non-run technological process of casting GTE turbine blades developed within the framework of the grant of Russian Science Foundation (project No. 20-79-00254), which is included in the projected 3D model for its subsequent compensation. The value of the volumetric shrinkage coefficient is calculated according to the relationship (1).

$$
\begin{gathered}
L_{\mathrm{B}}=L_{\mathrm{M}}-L_{\mathrm{M}} \cdot \beta=L_{\mathrm{M}}(1-\beta) ; \\
L_{л}=L_{\mathrm{B}}-L_{\mathrm{B}} \cdot \alpha=L_{\mathrm{B}}(1-\alpha)=L_{\mathrm{M}}(1-\alpha)(1-\beta) ; \\
L_{л}=L_{\mathrm{M}}-L_{\mathrm{M}}(\alpha+\beta)-L_{\mathrm{M}} \cdot \alpha \beta,
\end{gathered}
$$

where $\alpha$ is metal shrinkage coefficient, $\% ; \beta$ is wax shrinkage coefficient, $\% ; L_{\mathrm{B}}$ is overall size of a blade wax model, $\mathrm{mm} ; L_{\mathrm{J}}$ is overall size of the metal casting of the blade, $\mathrm{mm} ; L_{\mathrm{M}}$ is overall size of the grown model (master model) of the blade, mm.

In the process of designing a $3 \mathrm{D}$ model of a turbine blade blank, it is necessary to provide for the following design solutions:

- assign a total shrinkage factor of the material equal to $1.5 \%$;

- conduct spinning equal to $0.05 \mathrm{~mm}$ equidistant to the blade airfoil profile;

- $\quad$ add an allowance for tract surfaces equal to $0.5 \mathrm{~mm}$ per side;

- add an allowance equal to $0.5 \mathrm{~mm}$ to the leading and trailing edges of the blade;

- add an allowance of $1.5 \mathrm{~mm}$ per side on the surfaces forming the hinge area;

- design casting radial fillets of profile surfaces with the surfaces of the shelves $2 \pm$ $0.2 \mathrm{~mm}$;

- $\quad$ it is necessary to control with the built-in software tools the tolerance of the profile shape towards the profile thickening by $0.2 \mathrm{~mm}$, towards the profile thinning by $0.15 \mathrm{~mm}$.

For the surface of the airfoil, which is formed by a smooth transition between the given sections, it is necessary: 
- to ensure smooth transition of the leading and trailing edges, the fillets of the transition from the airfoil to the shelf;

- to combine the 3D model of the turbine blade casting and the 3D model of the rod (in the case of manufacturing turbine blades with a cooling channel). The elements of the rod protruding beyond the blade must be increased by at least $20 \mathrm{~mm}$ to form future seats of the ceramic rod when casting wax from a silicone mold (obtaining wax models of the blades). It is important that the elements protruding beyond the blade are angular for accurate positioning;

- $\quad$ assign an allowance for elements protruding beyond the blade at least $0.5 \mathrm{~mm}$.

Using the Objet Eden 350 3D printing system according to the patented PolyJet technology, a master model of a turbine blade blank was made from photopolymer material with an accuracy of 16 microns. When using this technology, it is important to know the algorithm of layer-by-layer synthesis of the model for its rational location on the construction platform in order to obtain the final product of maximum quality and with minimum shaping operations of mechanical processing [5 - 7].

An important advantage of using 3D printing technology is high speed of obtaining a prototype of a finished part and high quality of the product [8 - 10].

Control of geometric dimensions of the manufactured master model of the turbine blade blank showed deviation of the geometry of the blade airfoil profile relative to the given nominal position towards the thinning of the airfoil on average $-0.12 \mathrm{~mm}$, and towards the thickening of the blade $-0.26 \mathrm{~mm}$, which corresponds to the given tolerance for the executable size $[11,12]$.

Preparation for the stage of manufacturing silicone tooling must begin with completing the gating and feeding system (holes, feeders and other elements). At this stage, it is very important to calculate optimal geometric dimensions of all elements of the gating and feeding system in order to obtain, as a result, a uniform and defect-free nature of pouring molten wax mass into a silicone mold. Technologically, it is recommended to provide centering pins to give the silicone mold additional rigidity and increase stability of geometric dimensions of the blade casting (Figure 2).

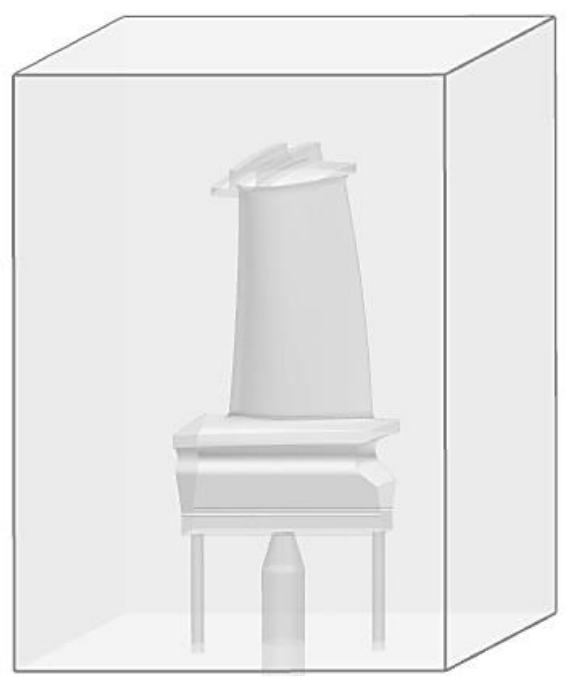

Fig. 2. Arrangement of a turbine blade blank with elements of a gating and feeding system in a silicone mold.

An important advantage of obtaining wax models of blades by casting into elastic silicone molds is the relative simplicity and manufacturability of the process. Even at the 
stage of preparing the master model, it is advisable to foresee and form future lines of parting of the mold. The entire technological cycle of preparation of technological tooling in the form of a silicone mold takes on average 1-2 working days, while with the traditional technology of obtaining wax models, when the metal tooling is designed and manufactured, the technological process can take up to six months. Among disadvantages of the technology used for casting wax model masses into an elastic silicone mold is its low durability. On average, from one silicone mold, it is possible to obtain 75-100 wax models, with geometric dimensions specified by technical documentation $[13,14]$.

The process of casting wax model mass into the manufactured silicone tooling consists of melting the wax to the required temperature and pouring it in a vacuum environment. The use of vacuum in this case makes it possible to compensate for the appearance of casting defects at the stage of manufacturing wax models of blades in the form of looseness and porosity.

With the help of computer modeling systems for casting processes, the results of uneven nature of volumetric shrinkage were obtained: direction and magnitude of shrinkage (Figure 3).

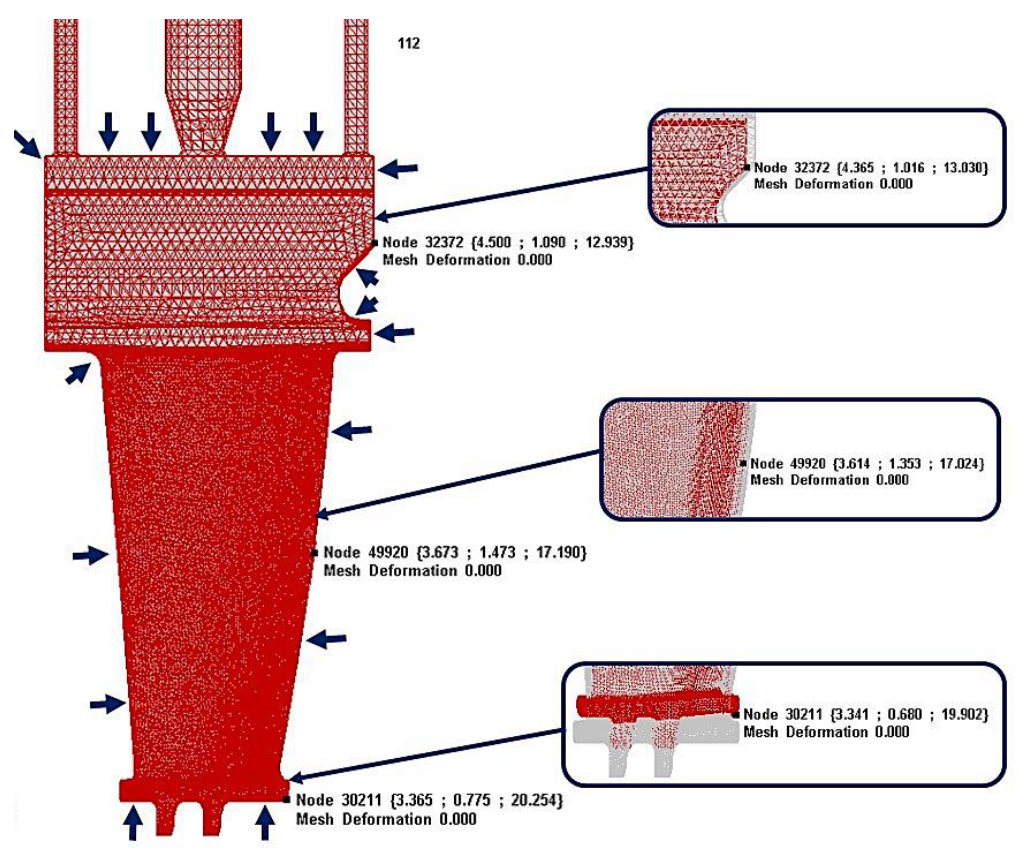

Fig. 3. Changing the geometry of the blade of a GTE in the process of volumetric shrinkage.

The wax models of the blanks of turbine blades of the GTE passed the control of geometric parameters on the coordinate measuring machine, according to the developed and agreed map of measurements. The blade airfoil profile was measured in three sections at a distance of 30,50 , and $75 \mathrm{~mm}$, respectively, from the hinge part $[15,16]$.

Analysis of the results of measuring the wax models of the blades showed that the smallest shrinkage value corresponds to the upper section located at a height of $75 \mathrm{~mm}$ from the hinge part. This can be explained by the fact that, due to the small thickness, the upper part of the blade cools down first, and the shrinkage cavity goes to the lower part, because the castle part is the most massive element. The smallest dimensional deviation (shrinkage) of the casting was obtained at a pouring temperature of the wax model mass equal to $95^{\circ} \mathrm{C}$. 


\section{Materials and equipment}

In the process of conducting experimental research, the following scientific equipment and materials were used. To manufacture a prototype (master model) of a GTE turbine blade blank, a 3D printing system Objet Eden 350 was used. As consumables, main purpose photopolymer materials FullCure 720 and auxiliary (support material) FullCure 705 were used, the principle of which is curing under the influence of ultraviolet exposure.

An Objet WaterJet was used to remove the support material by exposing the object to a jet of water under pressure, and a $10 \%$ caustic soda solution was used to dissolve the support material in hard-to-reach areas.

The stages of manufacturing a silicone elastic mold and pouring wax model masses were carried out using an MTT C 5/04 vacuum casting machine. The silicone elastic mold was made from the Pentelast-750 grade A compound of components A and B, which were mixed in proportions 1:1. For the manufacture of wax models of blade blanks, model wax Stavrol VM grade 3158 and Stavrol VM grade 155 were used.

The control of geometric dimensions of the master model and wax models of the blades was carried out by the contact method, implemented in the DEA GLOBAL Performance coordinate measuring machine.

\section{Results and discussion}

The developed innovative technological process for the production of blanks for wax models of GTE turbine blades using 3D printing technology and rapid prototyping methods made it possible to obtain wax models of blades in a short time and with maximum quality, which can be used in the traditional casting process with directional crystallization. The use of this technology enables for the development of technology of casting blades in production conditions. The developed technology will be relevant in the case of a multiproduct nature of production, which is characterized by iteration, frequent changes in the product design and a small batch of parts.

The research was supported by a grant of Russian Science Foundation (project № 20-79-00254).

\section{References}

1. Takeshi N 2014 Development of CMC turbine parts for aero engines Engineering Review 47(1) 29-32

2. Vdovin R A 2019 Improving the quality of the manufacturing process of turbine blades of the gas turbine engine Journal of Physics: Conference Series 1399(4) 044035

3. Belov P S, Dragina O G and Nikiforov D Yu 2014 The technological process of 3Dmodels manufacturing and pilot samples production by using fast prototyping technologies Machinery manufacturing technology 6 34-36

4. Vdovin R A 2020 Designing a duplicate model of the GTE turbine blade casting process IOP Conference Series: Materials Science and Engineering 709(3) 033073

5. Kiseleva A E 2017 Additive technologies application in shipbuilding design tasks Scientific and technical bulletin of Russian Maritime Register of Shipping 48-49 84-88

6. Vieira L F, Paggiand R A and Salmoria G V 2011 Thermal and dynamic-mechanical behavior of FullCure 3D printing resin post-cured by different methods Proc. of the 
5th Int. Conf. on Advanced Research in Virtual and Rapid prototyping vol 28 (Leiria, Boca Raton: CRC Press) pp 385-88

7. Guo N and Leu M C 2013 Additive manufacturing: technology, applications and research needs Front Mech Eng Cross Ref (View Record in Scopus Google Scholar) 8 215-243

8. Horn T J and Harrysson O L A 2012 Overview of current additive manufacturing technologies and selected applications Sci Progress (View Record in Scopus Google Scholar) 95 p. 255

9. Wong K V and Hernandez A 2012 A review of additive manufacturing ISRN Mech Eng (View Record in Scopus Google Scholar) p. 10

10. Smirnov D A and Balanduk I P 2015 Analysis of technologies for the printing process of FDM and POLYJET 3D-models Ural science and manufacturing 11 112-113

11. Bolotov M A, Pechenin V A and Ruzanov N V 2016 Uncertainties in measuring the compressor-blade profile in a gas-turbine engine Russian Engineering Research 36 (12) 1058-65

12. Pechenin V A, Bolotov M A and Rusanov N V 2014 Method of evaluation of profile form and shaped surfaces with application of wavelets Research Journal of Applied Sciences 9 (11) 820-824

13. Shumkov A A 2015 Fast prototyping technologies application for the medical implants manufacture Contemporary issues of science and education 2 (2) 146

14. Vdovin R A and Smelov V G 2017 Design and optimization of the micro-engine turbine rotor manufacturing using the rapid prototyping technology IOP Conference Series: Materials Science and Engineering 177(1) 6

15. Singh J P and Singh R 2009 Investigations for statistically controlled rapid casting solution of lead alloys using three dimensional printing Journal of Mechanical Engineering Sciences (Proc. of IMechE Part C) 223 2125-34

16. Singh J P and Singh R 2010 Comparison of statistically controlled rapid casting solutions of brass alloys using three dimensional printing Journal of Manufacturing Technology and Industrial Engineering 1 67-77 